Check for updates

Cite this: RSC Adv., 2017, 7, 44054

Received 11th July 2017

Accepted 7th September 2017

DOI: 10.1039/c7ra07635e

rsc.li/rsc-advances

\section{Surface plasmon resonance based competitive immunoassay for $\mathrm{Cd}^{2+} \uparrow$}

\author{
Gai-Feng Kang, (D) $t^{\mathrm{a}}$ Yu-Zhen Wang, (D) $t^{* \mathrm{~b}}$ Yun-Feng Bai, ${ }^{* \mathrm{~b}}$ Ze-Zhong Chen ${ }^{\mathrm{b}}$ \\ and Feng Feng ${ }^{\star a b}$
}

In this study, a label-free, specific and sensitive surface plasmon resonance (SPR) based competitive immunoassay was used for detecting $\mathrm{Cd}^{2+}$ in water samples. The standard curve of the method for $\mathrm{Cd}^{2+}$ was constructed in the concentration range of $0-1000 \mathrm{ng} \mathrm{mL}^{-1}$. The values of $\mathrm{IC}_{50}$ and the LOD of the assay were found to be 23.58 and $1.25 \mathrm{ng} \mathrm{mL}^{-1}$. No cross-reactivity was found with other metal ions except $\mathrm{Hg}^{2+}$. The proposed method provides an alternative method for sensitive, specific and real-time determination of $\mathrm{Cd}^{2+}$ in real aqueous samples.

\section{Introduction}

Cadmium is one of the most toxic heavy metals for human beings: it has great environmental and health impact and all cadmium compounds have been classified as human carcinogens. ${ }^{\mathbf{1} 2}$ Dietary intake of cadmium from water and crops in polluted environments results in various human diseases. ${ }^{3}$ Therefore, monitoring cadmium in water samples is urgently needed to protect human health and safety.

Up to now, cadmium can be determined by some classical and modern analytical methods, such as atomic absorption spectroscopy (AAS), ${ }^{4}$ inductively coupled plasma mass spectrometry (ICP-MS), ${ }^{5}$ Nonthermal Optical Emission Spectrometry, ${ }^{6}$ graphite furnace atomic absorption spectrometry (GF$\mathrm{AAS}){ }^{7}$ and miniature dielectric barrier discharge optical emission spectrometric (DBD-OES). ${ }^{8}$ These methods are sensitive and accurate, but there are some disadvantages for these approaches to detect the cadmium, such as longer consumption times, increased technical expertise and tedious sample pretreatments, and some labeling methods are not suitable in some cases, because labeling materials may occupy important binding sites or cause steric hindrance, resulting in false information.

Surface plasmon resonance (SPR) is an optical phenomenon occurred in total internal reflection of light at a metal filmliquid interface, ${ }^{9}$ which is one of the powerful analytical

${ }^{a}$ School of Chemistry and Materials Science, Shanxi Normal University, Linfen 041004, P. R. China. E-mail: feng-feng64@263.net; Fax: +86-352-610028; Tel: +86-3527158662

${ }^{b}$ College of Chemistry and Environmental Engineering, Shanxi Datong University, Datong 037009, P. R. China. E-mail: wyz2099610@126.com; Fax: +86-352-610028; Tel: $+86-352-7158662$

$\dagger$ Electronic supplementary information (ESI) available. See DOI: 10.1039/c7ra07635e

\$ These authors contributed equally to this work. techniques for direct monitoring of molecular interactions. SPR is based on measuring binding-induced changes in refractive index and this platform thus allows for label-free, real-time analysis of the target molecules. In recent years, SPR has been applied in drug discovery, ${ }^{\mathbf{1 0}}$ biomarkers screening, ${ }^{\mathbf{1 1}}$ food safety $^{12,13}$ and environmental monitoring. ${ }^{14,15}$

Besides, the immunological detection method based on antigen-antibody has provided a new strategy for the detection of cadmium pollution, and there have been many reports about the immunoassay of cadmium. ${ }^{16-18}$ The members of our research group have also established many methods for detecting metal ions. ${ }^{\mathbf{1 9 - 2 4}}$

Herein, we report a specific and sensitive competitive immunoassay combined SPR for the detection of cadmium $\left(\mathrm{Cd}^{2+}\right)$ in aqueous solution for the first time. At present, all antibodies specific for cadmium recognize a chelated form of $\mathrm{Cd}^{2+}$, that is, Cd-EDTA. ${ }^{25-29}$ In our previous study, cadmium ion was respectively coupled to carrier protein (bovine serum albumin, BSA; ovalbumin, OVA) via a phenyl isothiocyanateEDTA (ITCBE) to form the immunogen (Cd-ITCBE-BSA) and coating antigen (Cd-ITCBE-OVA). Using the hybridoma technique we successfully produced monoclonal antibody (mAb) against $\mathrm{Cd}^{2+}$, which were then characterized by an indirect competitive enzyme linked immunosorbent assay (ELISA). ${ }^{30}$ Combining the specific mAb with the sensitive and lable-free analytical SPR method, we expect that the SPR based immunoassay will be able to rapid detect $\mathrm{Cd}^{2+}$ with high sensitivity and specificity.

\section{Experimental}

\subsection{Chemicals and reagents}

$N$-Hydroxysuccinimide (NHS), $N$-(3-dimethylaminopropyl)- $N^{\prime}$ ethylcarbodiimide hydrochloride (EDC), 4-(2-hydroxyethyl)-1piper-azineethanesulfonic acid (HEPES), bovine serum 
albumin (BSA), chicken egg albumin (OVA), ethanolamine ( $\geqq 98 \%$ ), glycine (Vetec ${ }^{\mathrm{TM}}$ reagent grade, 98\%) were purchased from Aladdin (Shanghai, China). All other chemical reagents were of analytical grade and used without further purification. The antigen and antibody were self-made in this experiment. Detection experiment of $\mathrm{Cd}^{2+}$ in real aqueous samples, lake water sample was collected from Wenying Lake in Datong city and tap water was obtained from our laboratory. In this work, $10 \mathrm{mM}$ HEPES buffer ( $\mathrm{pH}$ 7.4) containing $150 \mathrm{mM} \mathrm{NaCl}, 3 \mathrm{mM}$ EDTA, $0.005 \%$ (v/v) surfactant P20 was employed as running buffer and $10 \mathrm{mM}$ acetate buffer solution was used as coupling buffer. Ultrapure water was used for the preparation of aqueous solutions.

\subsection{Instrumentation}

The Biacore $\mathrm{X}^{\mathrm{TM}}$ (Uppsala, Sweden) and CM5 sensor chip were used for all in situ surface bioaffinity detection. All solutions for experiments were filtered by $0.22 \mu \mathrm{m}$ microporous membrane and degassed before use. Running buffer was HBS-EP buffer solution ( $\mathrm{pH} 7.4$ ) throughout the instrument at $10 \mu \mathrm{L} \mathrm{min} \mathrm{m}^{-1}$ flow rate. CM5 sensor chips and all solutions were kept at room temperature before use.

\subsection{Immobilization of antigen}

Many methods of antibody immobilization used in SPR have been developed, ${ }^{31,32}$ however, the antigen was immobilized to determine $\mathrm{Cd}^{2+}$ in this experiment. Under optimal assay conditions, the self-made coating antigen (Cd-ITCBE-OVA) immobilization experiment was carried out at first, the whole process are shown in Fig. 1. A sensor chip CM5 was docked into the Biacore instrument firstly and primed with running buffer (HBS-EP, pH 7.4) at $10 \mu \mathrm{L} \mathrm{min}^{-1}$ flow rate. The EDC/NHS mixed solution was injected $\left(70 \mu \mathrm{L}, 10 \mu \mathrm{L} \min ^{-1}\right)$ to activate the surface of the sensor chip CM5. This was immediately followed by immobilization antigen (Cd-ITCBE-OVA) (70 $\mu \mathrm{L}$,

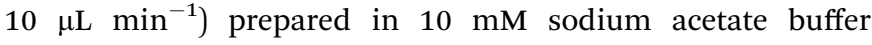
(pH 3.75). Then the remaining activate sites of the sensor chip CM5 surface was blocked with $70 \mu \mathrm{L}$ ethanolamine ( $\mathrm{pH}$ 8.5). In this way, the immobilization of antigen was completed.

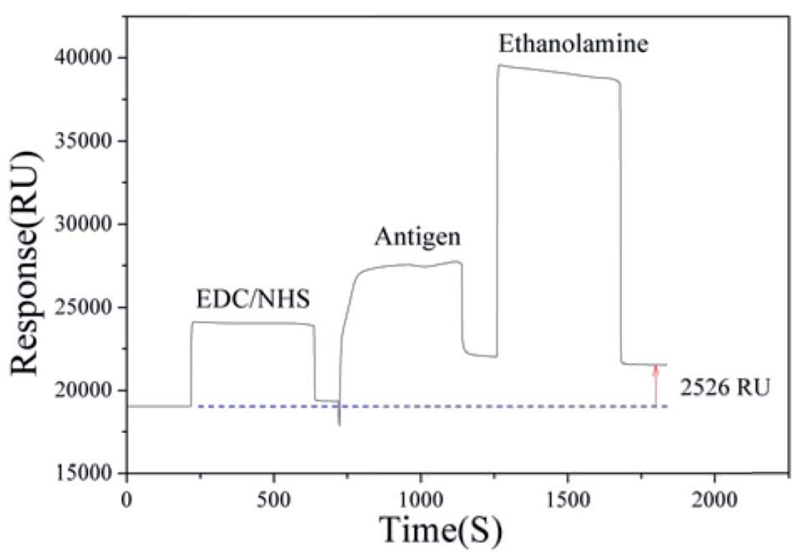

Fig. 1 Immobilization of the antigen.

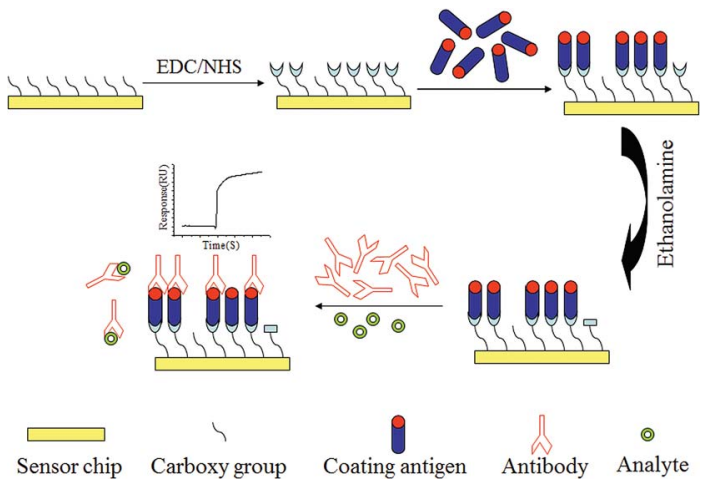

Scheme 1 The principle and process of the SPR based competitive immunoassay for $\mathrm{Cd}^{2+}$.

Eventually, it was found that the corresponding signal value of the combinative amount of antigen was $2526 \mathrm{RU}$.

\subsection{The whole process of $\mathrm{Cd}^{2+}$ detection assay}

The principle and process of the method are illustrated in Scheme 1. The CM5 dextran chip surface was firstly activated by EDC/NHS solution, after the coating antigen was immobilized, then the surface was deactivated with ethanolamine. The coating antigen competed for the mAbs with $\mathrm{Cd}^{2+}$ in the solution. The SPR response change decreased due to the less amount of the mAbs bound on the chip surface, which was caused by the competition of the high concentration of $\mathrm{Cd}^{2+}$ in the solution.

\section{Results and discussion}

In order to obtain much more sensitive results in this study, the SPR relevant experimental conditions were optimized respectively before the antigen binding experiment. To select the optimal $\mathrm{pH}$ value of acetate buffer solution (the antigen diluent), nine parallel experiments were measured so that the corresponding signals were obtained, as shown in Fig. S1 (ESI $\dagger$ ), it was seen that the corresponding signal of $\mathrm{pH}$ value 3.75 was the strongest one, so the acetate buffer solution of $\mathrm{pH}$ value 3.75 was selected. Then choosing the appropriate antigen concentration, five experiments with different antigen dilution rates were carried out, as exhibited in Fig. S2 (ESI $\dagger$ ), it was seen that with the dilution rate increasing, the response values were significantly decreased, but due to the high cost of antigen, resulting in 1:10 antigen dilution rate was selected. Finally, four parallel experiments with different flow rates were measured respectively, as exhibited in Fig. S3 (ESI $\dagger$ ), the $10 \mu \mathrm{L} \mathrm{min}{ }^{-1}$ flow rate was chosen after comprehensive consideration. After screening, it was concluded that the results were satisfactory under these optimal conditions.

The resulting chip above was used as a sensing surface for detecting $\mathrm{Cd}^{2+}$. The mixed solution $(\mathrm{v} / \mathrm{v}=1: 1)$ of the cadmium $\mathrm{mAb}$ solution and Cd-EDTA standard solution was prepared, and Cd-EDTA standard solution was diluted into different concentration with HBS-EP before mixing. These solutions

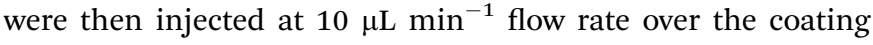


antigen (Cd-ITCBA-OVA) modified surface for $3 \mathrm{~min}$ to allow binding assays. Following this, the sensor surface was regenerated by injected $10 \mu \mathrm{L} 10 \mathrm{mM}$ glycine- $\mathrm{HCl}(\mathrm{pH}$ 1.7). The corresponding signals and the calibration curve of the SPR based immunoassay for $\mathrm{Cd}^{2+}$ in different standard concentrations are shown in Fig. 2 and 3. It was found that the SPR signal steadily decreased as the concentration of $\mathrm{Cd}^{2+}$ increased. The $\mathrm{IC}_{50}$ value was found to be $23.58 \mathrm{ng} \mathrm{mL} \mathrm{mL}^{-1}$, the limit of detection (LOD) was $1.25 \mathrm{ng} \mathrm{mL} \mathrm{m}^{-1}$ and the linear range of concentration was 3.57-758.37 $\mathrm{ng} \mathrm{mL}^{-1}$. Compared with other methods for $\mathrm{Cd}^{2+}$ detection, our method had a similar or superior linear range and detection limit (Table S1, ESI†).

In order to demonstrate the binding of cadmium mAbs to $\mathrm{Cd}^{2+}$ was specific, metal ions such as $\mathrm{Cu}^{2+}, \mathrm{Ni}^{2+}, \mathrm{Co}^{2+}, \mathrm{Cr}^{3+}, \mathrm{Pb}^{2+}$, $\mathrm{Mg}^{2+}$ and $\mathrm{Zn}^{2+}$ were selected to test the cross-reactivity. The concentration of the cross-reacting ions were $0-1000 \mathrm{ng} \mathrm{mL}{ }^{-1}$ and applied according to the procedure of the assay, as shown in Fig. 4. One could conclude that no cross-reactivity of the mAbs with $\mathrm{Cu}^{2+}, \mathrm{Ni}^{2+}, \mathrm{Co}^{2+}, \mathrm{Cr}^{3+}, \mathrm{Pb}^{2+}, \mathrm{Mg}^{2+}$ and $\mathrm{Zn}^{2+}$ respectively, but the cross-reactivity of the mAbs with $\mathrm{Hg}^{2+}$ was $73.12 \%$, which was actually rather serious. The results obtained in this approach were similar to the ELISA using the same mAb. ${ }^{30}$ It could be caused by the spatial configuration of the chelates that is respectively formed by $\mathrm{Hg}^{2+}$ and $\mathrm{Cd}^{2+}$ with EDTA are quite similar and the interactions of the chelates with the antibody.

The practical application of the proposed biosensor was evaluated in lake water and tap water. Samples of lake water and tap water were collected from the Wenying Lake and our laboratory, respectively. Prior to testing, the collected water samples were filtered by $0.22 \mu \mathrm{m}$ filter membrane to remove insoluble substances. Then, the SPR based competitive immunoassay was applied to detect the filtrates which were spiked with Cd-EDTA at the concentration of $10 \mathrm{ng} \mathrm{mL}{ }^{-1}, 20 \mathrm{ng} \mathrm{mL}^{-1}$ and $50 \mathrm{ng} \mathrm{mL}^{-1}$, respectively. Acceptable recovery rates of $96.80-102.37 \%$ were obtained (as shown in Table 1), which suggested that

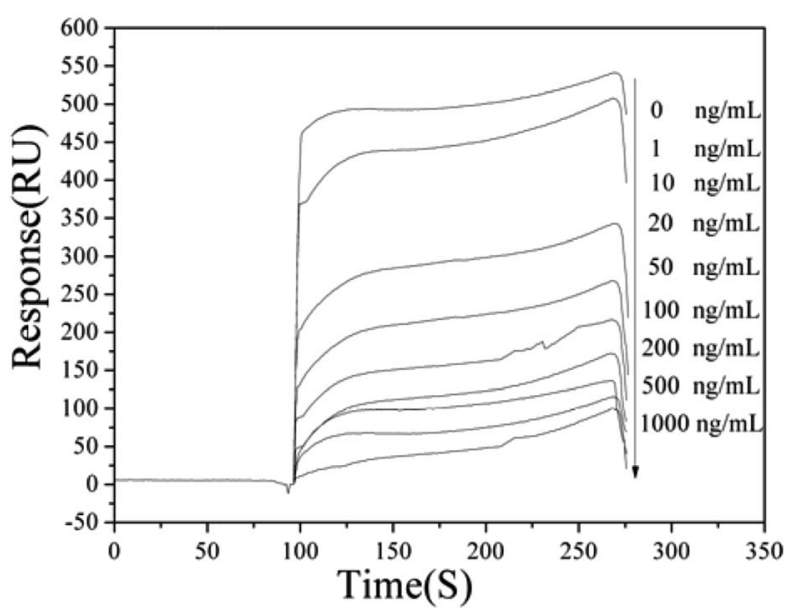

Fig. 2 The SPR signals of the SPR based immunoassay for $\mathrm{Cd}^{2+}$ with different standard concentrations. The arrow shows the signal changes with increasing Cd-EDTA concentrations $(0,1,10,20,50$, $100,200,500,1000 \mathrm{ng} \mathrm{mL}^{-1}$ ).

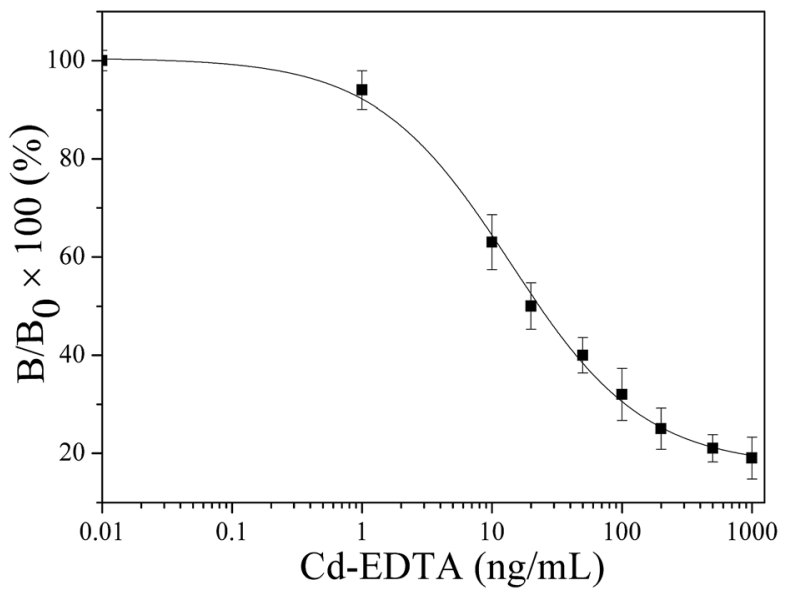

Fig. 3 The calibration curve of the SPR based immunoassay for $\mathrm{Cd}^{2+}$ with different standard concentrations, where $B$ and $B_{0}$ are the SPR signals of the analyte at the standard point and at the zero concentration of the analyte, respectively.

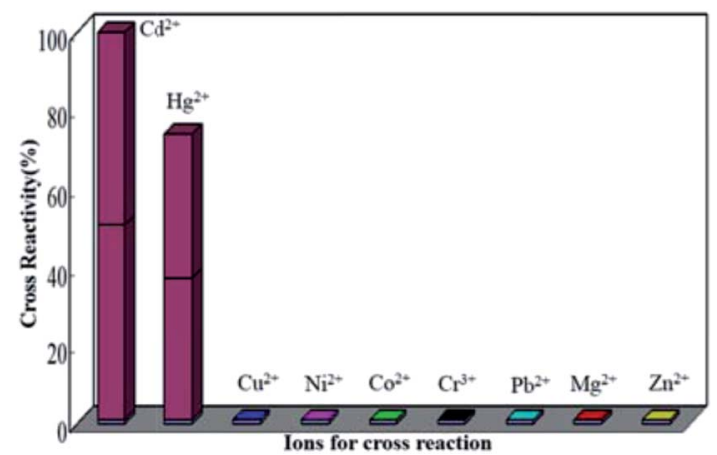

Fig. 4 The cross-reactivity values of the monoclonal antibody with $\mathrm{Cd}^{2+}$ and other ions tested by the proposed SPR based competitive immunoassay.

the method could be used for the detection of $\mathrm{Cd}^{2+}$ in real aqueous samples.

Note that various cellphone (CP)-based technologies have been developed for multifarious applications. ${ }^{33-35}$ What's more, combining an angle-resolved SPR detection system with cellphone-based devices (CBDs) has been developed and employed for the detection of $\beta_{2}$ microglobulin $\left(\beta_{2} \mathrm{M}\right){ }^{36}$ and a good analysis result was obtained. Hence, in the near future,

Table 1 Determination of $\mathrm{Cd}^{2+}$ in water samples using the proposed method

\begin{tabular}{|c|c|c|c|}
\hline Samples & Added $\left(\mathrm{ng} \mathrm{mL}^{-1}\right)$ & $\begin{array}{l}\text { Found, mean } \pm \\
\mathrm{SD}\left(\mathrm{ng} \mathrm{mL}^{-1}, n=3\right)\end{array}$ & Recovery (\%) \\
\hline \multirow[t]{3}{*}{ Lake water } & 10 & $9.85 \pm 0.63$ & 98.54 \\
\hline & 20 & $19.36 \pm 1.12$ & 96.80 \\
\hline & 50 & $48.42 \pm 3.07$ & 96.84 \\
\hline \multirow[t]{3}{*}{ Tap water } & 10 & $10.24 \pm 0.59$ & 102.37 \\
\hline & 20 & $19.52 \pm 1.23$ & 97.60 \\
\hline & 50 & $49.16 \pm 2.85$ & 98.31 \\
\hline
\end{tabular}


heavy metal ions may also be detected by combining SPR with CBDs technique so that develop a prospective upcoming devices in the environmental and food monitoring.

\section{Conclusions}

In summary, a sensitive and specific SPR based competitive immunoassay for the detection of $\mathrm{Cd}^{2+}$ was developed. It provided a new theoretical and technical support for the detection of heavy metal ions. Based on this novel method, the values of $\mathrm{IC}_{50}\left(23.58 \mathrm{ng} \mathrm{mL} \mathrm{m}^{-1}\right)$ and LOD $\left(1.25 \mathrm{ng} \mathrm{mL} \mathrm{mL}^{-1}\right)$ were obtained. In addition to $\mathrm{Hg}^{2+}$, this method showed good selectivity for $\mathrm{Cd}^{2+}$ without interference of some other heavy metal ions. Moreover, the sensing strategy could real-time monitor and shorten the analytical time, which is shorter than previously reported methods. ${ }^{37-40}$ This novel biosensor approach not only provides an alternative, sensitive and specific analytical method for the detection of $\mathrm{Cd}^{2+}$, but can also be extended as a useful model for the detection of other small molecular compounds in biological, food and environmental areas.

\section{Conflicts of interest}

There are no conflicts of interest to declare.

\section{Acknowledgements}

This work was supported by the National Natural Science Foundation of China (21375083), Key Scientific and Technological Projects of Datong City (2015025, 2015023), Scientific and Technological Innovation Programs of Higher Education Institutions in Shanxi (2015179) and Doctoral Scientific Research projects of Shanxi Datong University (2012-B-08, 2014B-03).

\section{Notes and references}

1 A. A. Newairy, A. S. El-Sharaky, M. M. Badreldeen, S. M. Eweda and S. A. Sheweita, Toxicology, 2007, 242, 23.

2 S. Nemmiche, D. Chabane-Sari, M. Kadri and P. Guiraud, Toxicol. In Vitro, 2011, 25, 191.

3 M. J. Scoullos, G. H. Vonkeman, I. Thornton and Z. Makuch, Mercury-Cadmium-Lead: Handbook for Sustainable Heavy Metals Policy and Regulation, Springer, Netherlands, 2001.

4 (a) J. Gasparik, D. Vladarova, M. Capcarova, P. Smehyl, J. Slamecka and P. Garaj, J. Environ. Sci. Health, Part A: Toxic/Hazard. Subst. Environ. Eng., 2010, 45, 818; (b) P. Pohl, TrAC, Trends Anal. Chem., 2009, 28, 117.

5 (a) C. Cloquet, J. Carignan, G. Libourel, T. Sterckeman and E. Perdrix, Environ. Sci. Technol., 2006, 40, 2525; (b) S. P. Dolan, D. A. Nortrup, P. M. Bolger and S. G. Capar, J. Agric. Food Chem., 2003, 51, 1307; (c) M. Grau-Perez, G. Pichler, I. Galan-Chilet, L. S. Briongos-Figuero, P. Rentero-Garrido and R. Lopez-Izquierdo, Environ. Int, 2017, 106, 27.
6 Y. Cai, Y. J. Zhang, D. F. Wu, Y. L. Yu and J. H. Wang, Anal. Chem., 2016, 88, 4192.

7 J. E. L. Villa, R. R. A. Peixoto and S. Cadore, J. Agric. Food Chem., 2014, 62, 8759.

8 Y. J. Zhang, Y. Cai, Y. L. Yu and J. H. Wang, Anal. Chim. Acta, 2017, 976, 45.

9 M. Piliarik, H. Vaisocherova and J. Homola, Methods Mol. Biol., 2009, 503, 65.

10 Y. Fang, Expert Opin. Drug Discovery, 2012, 7, 969.

11 A. Shabani and M. Tabrizian, Analyst, 2013, 138, 6052.

12 C. Situ, J. Buijs, M. H. Mooney and C. T. Elliott, TrAC, Trends Anal. Chem., 2010, 29, 1305.

13 M. Piliarik, L. Párová and J. Homola, Biosens. Bioelectron., 2009, 24, 1399.

14 R. Yatabe, T. Onodera and K. Toko, Sensors, 2013, 13, 9294.

15 S. Scarano, M. Mascini, A. P. F. Turner and M. Minunni, Biosens. Bioelectron., 2010, 25, 957.

16 K. Abe, K. Nakamura and T. Arao, J. Sci. Food Agric., 2011, 91, 1392.

17 K. Sasaki, N. Yongvongsoontorn and K. Tawarada, J. Agric. Food Chem., 2009, 57, 4514.

18 I. A. Darwish and D. A. Blake, Anal. Chem., 2001, 73, 1889.

19 J. Qin, X. M. Li, Z. Chen and F. Feng, Sens. Actuators, B, 2016, 232, 611.

20 Y. H. Yuan, M. Z. Tian, J. L. Wang, H. Xie, J. Qin and F. Feng, RSC Adv., 2015, 5, 69453.

21 Y. F. Bai, L. Zhao, Z. Chen, H. Y. Wang and F. Feng, Anal. Methods, 2014, 6, 8120.

22 Y. F. Bai, F. Feng, L. Zhao, Z. Chen, H. Y. Wang and Y. L. Duan, Anal. Methods, 2014, 6, 662.

23 Y. Z. Wang, S. Chen, C. Wei, M. M. Xu, J. L. Yao, Y. Li, A. P. Deng and R. N. Gu, Chem. Commun., 2014, 50, 9112.

24 Y. Z. Wang, H. Yang, M. Pschenitza, R. Niessner, Y. Li, D. Knopp and A. P. Deng, Anal. Bioanal. Chem., 2012, 403, 2519.

25 D. A. Blake, P. Chakrabarti, M. Khosraviani, F. M. Hatcher, C. M. Westhoff, P. Goebel, D. E. Wylie and R. C. Blake, J. Biol. Chem., 1996, 271, 27677.

26 K. Tawarada, K. Sasaki, N. Ohmura, N. Matsumoto and H. Saiki, Bunseki Kagaku, 2003, 52, 583.

27 K. Sasaki, K. Tawarada, A. Okuyama, K. F. ayama, K. Abe, H. Okuhata, Y. Maruyama, T. Arakane, H. Miyasaka, T. Fujikawa and N. Ohmura, Bunseki Kagaku, 2007, 56, 29.

28 X. Zhu, L. Xu, H. Yu, X. Li, D. A. Blake and F. Liu, J. Agric. Food Chem., 2007, 55, 7648.

29 K. Sasaki, N. Yongvongsoontorn, K. Tawarada, Y. Ohnisni, T. Arakane, F. Kayama, K. Abe, S. Oguma and N. Ohmura, J. Agric. Food Chem., 2009, 57, 4514.

30 J. Q. Zhou, F. Feng, Y. Z. Wang and A. P. Deng, Chem. Res. Appl., 2016, 28, 432.

31 S. K. Vashist, C. K. Dixit, B. D. MacCraith and R. O'Kennedy, Analyst, 2011, 136, 4431.

32 S. K. Vashist, E. M. Schneider and J. H. T. Luong, Analyst, 2014, 139, 2237. 
33 S. K. Vashist, O. Mudanyali, E. M. Schneider, R. Zengerle and A. Ozcan, Anal. Bioanal. Chem., 2014, 406, 3263.

34 A. Ozcan, Lab Chip, 2014, 14, 3187.

35 S. K. Vashist, P. B. Luppa, L. Y. Yeo, A. Ozcan and J. H. Luong, Trends Biotechnol., 2015, 33, 692.

36 P. Preechaburana, M. C. Gonzalez, A. Suska and D. Filippini, Angew. Chem., 2012, 124, 11753.

37 L. Z. Zhao, M. Li, M. M. Liu, Y. C. Zhang, C. L. Wu and Y. Z. Zhang, J. Hazard. Mater., 2016, 301, 233.
38 K. Duarte, C. I. L. Justino, A. C. Freitas, A. M. P. Gomes, A. C. Duarte and T. A. P. Rocha-Santos, TrAC, Trends Anal. Chem., 2015, 64, 183.

39 E. Nagles, V. Arancibia, R. Ríos and C. Rojas, Int. J. Electrochem. Sci., 2012, 7, 5521.

40 M. C. Talio, M. Alesso, M. Acosta, V. S. Wills and L. P. Fernández, Talanta, 2017, 174, 221. 